\title{
A Predicative Study in the Light of Angular Kinematic Variables of Body Joints during the Hop in Triple Jump
}

\section{Dr. Wahid Sobhy Abd El-Ghaffar ${ }^{1}$}

\section{Abstract:}

The current research aims at concluding predicative equations for the performance level of triple jump in the light of some angular kinematic variables through identifying the correlation between angular kinematic variables and digital record during the hop phase in triple jump and the relative contribution of angular kinematic variables of the hop phase in digital record of triple jump in addition to concluding predicative equations for the digital record through angular kinematic variables of the hop phase in triple jump. The researcher used the descriptive (analytical) approach. The researcher purposefully chose triple jump finalists of Egypt's Track and Field Championship (first class) $2013 \quad(n=6)$. The best Three trials for each athlete were recorded and this makes (18) trials for analysis. Results indicated that indicators contributing in the digital record at the beginning of damping for first takeoff are knee angular displacement, shoulder angular displacement, hip angular acceleration, ankle angular displacement and knee angular acceleration. Indicators contributing in the digital record at the beginning of damping for second takeoff are elbow angular displacement and ankle angular acceleration. Indicators contributing in the digital record at the end of damping/ beginning of pushing for first takeoff are ankle angular velocity and knee angular displacement. Indicators contributing in the digital record at the end of damping/ beginning of pushing for second takeoff are knee angular displacement, ankle angular displacement, shoulder angular displacement and ankle angular acceleration. Indicators contributing in the digital record at the end of pushing for first takeoff are hip angular displacement, wrest angular acceleration, shoulder angular

${ }^{1}$ Lecturer, kinesiology Department - Faculty of Physical Education - Kafr AlShaikh University 
displacement, ankle angular velocity, wrest angular displacement, elbow angular acceleration and hip angular velocity. Indicators contributing in the digital record at the end of pushing for first takeoff are ankle angular displacement, ankle angular velocity and hip angular displacement.

Key words: Indicator Angular Kinematic Indicators

Background:

Scientific approach is the base for reaching elite performance levels in sport. Scientific research is of major importance as it may lead to results that represent an addition to science. This importance increases as it can be used in achieving sports advances via increasing performance efficiency to higher level $(6: 12,18)$.

Swasan Abd Al-Monem et al (1991), Adel Abd El-Basir (1998), Al-Sabbagh \& Alaa ElDin (1999), Owais Al-Gebaly (2001) and Berequaa \& AlSokkary (2002) indicated that sports biomechanics focuses on studying and analyzing motor performance to achieve the best biomechanical solutions for motor problems under investigation. This deepens coaches' and athletes' knowledge about details of movements and the ways to learn, perform and improve them in addition to designing specific exercises in the light of biomechanical analysis (2: 14) (8: 210) (9: 5) (7: 96) (12: 32).

Triple Jump is a major event that is affected greatly with the advances of motor analysis for champions' performance to identify optimum technique with the aim of improving specific learning and training programs. This is not a new trend but it has become very important recently. This indicates the importance of biomechanical analysis of triple jump. Performance levels of this event have reached impressive quantitative and qualitative levels worldwide. This is due to the use of scientific approaches in teaching and training.

Egypt is still underrepresented in international and Olympic championships in this event. This indicates the importance of finding out the best ways to improve the performance level of triple 
jump, in the light of modern training philosophy of integrated improvement of the athlete.

Table (1): The decreased level of Egyptian Triple Jumpers on the Arab, African, World and Olympic Levels (world record: $18.29 \mathrm{~m}$ )

\begin{tabular}{c|c|c|c|c|c|c}
\hline \hline Championship & Country & Date & Place & $\begin{array}{c}\text { Champion } \\
\text { record }\end{array}$ & $\begin{array}{c}\text { Number } \\
\text { of } \\
\text { Egyptian } \\
\text { athletes }\end{array}$ & Rank \\
\hline \hline $\begin{array}{c}\text { African } \\
\text { Championship } \\
\text { for Athletics }\end{array}$ & Benin & $\begin{array}{c}27 / 6 \text { to } \\
1 / 7 / 2012\end{array}$ & $\begin{array}{c}\text { Charles } \\
\text { Digul } \\
\text { stadium }\end{array}$ & $16.98 \mathrm{~m}$ & 1 & 7 \\
\hline $\begin{array}{c}2012 \text { Olympic } \\
\text { Games }\end{array}$ & $\begin{array}{c}\text { London } \\
\text { England }\end{array}$ & $\begin{array}{c}2- \\
12 / 8 / 2012\end{array}$ & $\begin{array}{c}\text { Olympic } \\
\text { court }\end{array}$ & $17.81 \mathrm{~m}$ & 0 & 0 \\
\hline $\begin{array}{c}\text { Arab } \\
\text { Championship } \\
\text { for Athletics }\end{array}$ & $\begin{array}{c}\text { Doha } \\
\text { Qatar }\end{array}$ & $\begin{array}{c}21- \\
25 / 5 / 2013\end{array}$ & $\begin{array}{c}\text { Qatar } \\
\text { stadium }\end{array}$ & $17.01 \mathrm{~m}$ & 1 & 4 \\
\hline $\begin{array}{c}14^{\text {th }} \text { World } \\
\text { Championship } \\
\text { for Athletics }\end{array}$ & $\begin{array}{c}\text { Moscow } \\
\text { Russia }\end{array}$ & $10-$ & $\begin{array}{c}\text { Losniki } \\
18 / 8 / 2013\end{array}$ & $7.20 \mathrm{~m}$ & 0 & 0 \\
\hline \hline
\end{tabular}

(25) (26) (27) (28) (29)

This

underrepresentation of Egypt is due to the lack of objective sciencebased teaching and training programs that depend on results of biomechanical analysis for elite athletes in addition to using predictive equations through angular kinematic variables of body joints during the hop for triple jumpers.

Technique of triple jump requires that the jumper should push the floor hard with the takeoff foot then land on the same foot (during the hop). This indicates the importance of this foot according to flexion, extension and eccentric/concentric muscular work. This also indicates the importance of angular kinematics of body joints during this critical stage of movement.

$$
\text { Jae et al (1995) }
$$
performed a kinematic analysis of triple jump. Hay (1997) investigated the relative distance of shapes and triple jump technique for 1996 Olympic Games' Men events. Jihan Hamed (2010) investigated some biomechanical variables of 
pivoting phases in triple jump and its relation to flight trajectory and performance level. Moamer Adam (2010) performed a biomechanical analysis for Sudanese Triple Jumpers. (17) (14) (4) (10).

Mohamed Khalil (1993) indicated that the hop is longest phase of triple jump as it represents $39 \%$ while the step represents $30 \%$ and the bounce represents $31 \%$. Adrian \& Cooper (1995) indicated that the phases of Russian triple jump are $38 \%$ for the hop, $29 \%$ for the step and $33 \%$ for the bounce. Abd El-Halim et al (2003) indicated that the optimum ratio is $37 \%$ for the hop, $29 \%$ for the step and $34 \%$ for the bounce (18: 16) (5: 320, 323) (1: 132).

This makes the hop the most important phase of triple jump as it effects the jump distance effectively. Through review of literature, the researcher did not find any previous study that relates angular kinematic variables of body joints during the hop and the digital record of triple jump. This led the researcher to perform a predicative study in the light of some angular kinematic variables of body joints during the hop in triple jump.

Aim:

The current research aims at concluding predicative equations for the performance level of triple jump in the light of some angular kinematic variables through:

1. Identifying the correlation between angular kinematic variables and digital record during the hop phase in triple jump

2. Identifying the relative contribution of angular kinematic variables of the hop phase in digital record of triple jump

Hypotheses:

1. There is a correlation between angular kinematic variables and digital record during the hop phase in triple jump.

2. Relative contributions of angular kinematic variables of the hop phase in digital record of triple jump vary.

3. The digital record can be predicted through angular kinematic 
variables of the hop

Methods:

Approach:

The researcher used the descriptive (analytical) approach.

\section{Participants:}

The researcher chose (9) athletes purposefully. These athletes were divided into (3) athletes for the pilot study and (6) athletes (finalists of Egypt's Athletics Championship 2013 first class). The best (3) trials for each athlete were recorded. This makes total of (18) trials.

Tools:

The researcher used motor analysis and motor recording tools in addition to triple jump tools and some anthropometric measurements.

\section{Pilot Study:}

Motor analysis procedures:

- All athletes were equipped with markers for biomechanical analysis

- According to results of pilot study, (1) highspeed camera was fixed vertically on tripod on the left side of athletes, phase in triple jump.

Pilot study was performed on (3) athletes from the same research community and outside the main sample on 24-4-2013 at the field of the Olympic Center - Maady to identify criteria of recording performance and calibrate all tools.

\section{Main study:}

- Performance was recorded for all athletes on 25-4-2013

- DMAS7 software was used to identify the part to be analyzed (hop phase with first and second takeoff)

- Three moments were chosen for analysis (beginning of damping - end of damping/beginning of pushing - end of pushing).

$10.5 \mathrm{~m}$ away from the approach path. Height of lens from ground was $1.27 \mathrm{~m}$

- The camera was fixed $5.45 \mathrm{~m}$ from the takeoff board on the half of thee hop.

- The camera was set on $120 \mathrm{c} / \mathrm{sec}$ and was 
attached to DMAS7 to record (live)

- Calibration device was videotaped right in the middle of movement scope and then removed

- Trials of each athlete were recorded

- Failed trials were excluded

Only the best two trials for each athlete were taken for analysis 
Results:

Table (2) 


\section{0}

Table (3)

Predicative equations: $\quad(\mathrm{Y}=$ dependent variable $-\mathrm{A}=$ constant $-\mathrm{B}=$ regression coefficient $-\mathrm{X}=$ independent variable)

1. Digital record $=4.8257$

$+(0.06354 \mathrm{x}$ knee angular displacement) $[\mathrm{Y}=\mathrm{A}+\mathrm{BX}]$

2. Digital record $=6.1784$ $+(0.04957 \mathrm{x}$ knee angular displacement $)+(0.02112 \mathrm{x}$ shoulder angular displacement) [Y=A+B1x 1+B2x2]

3. Digital record $=7.7985$

$+(0.03838 \times$ knee angular displacement $)+(0.02183 \mathrm{x}$ shoulder angular displacement) $+(-0.00004 \times$ hip angular acceleration)

$[\mathrm{Y}=\mathrm{A}+\mathrm{B} 1 \mathrm{x} 1+\mathrm{B} 2 \mathrm{x} 2+\mathrm{B} 3 \mathrm{x} 3]$
4. Digital record $=7.5054$

$+(0.06706 \mathrm{x}$ knee angular displacement $)+(0.00624 \mathrm{x}$ shoulder angular displacement) $+(-0.00006$ x hip angular acceleration $)+(-0.02854 \mathrm{x}$ ankle angular displacement $[\mathrm{Y}=\mathrm{A}+\mathrm{B} 1 \mathrm{x} 1+\mathrm{B} 2 \mathrm{x} 2+\mathrm{B} 3 \mathrm{x} 3+\mathrm{B} 4$ $\mathrm{X} 4]$

5. Digital record $=8.8261$

$+(0.08301 \mathrm{x}$ knee angular displacement $)+(0.01207 \mathrm{x}$ shoulder angular displacement) $+(-0.00007 \times$ hip angular acceleration $)+(-0.05460 \mathrm{x}$ ankle angular displacement $+(-$ $0.00003 \mathrm{x}$ knee angular acceleration) $[\mathrm{Y}=\mathrm{A}+\mathrm{B} 1 \mathrm{x} 1+\mathrm{B} 2 \mathrm{x} 2+\mathrm{B} 3 \mathrm{x} 3+\mathrm{B} 4$ $\mathrm{x} 4+\mathrm{B} 5 \mathrm{x} 5]$ 
Table (4) 
Table (5)

Predicative equations:

Digital record $=11.6888+-$ $0.0077 \mathrm{X}$ Ankle angular velocity) $[\mathrm{Y}=\mathrm{A}=\mathrm{BX}]$
- $\quad$ Digital record $=19.6456$ $+(-0.0042 \mathrm{x}$ Ankle angular velocity $)+(-0.0465 \times$ Knee angular displacement) $[\mathrm{Y}=\mathrm{A}=\mathrm{B} 1 \mathrm{x} 1+\mathrm{B} 2 \mathrm{x} 2]$ 
Table (6) 
Table (7) 
Predicative equations:

1 - $\quad$ Digital record $=3.1284$

$+\quad(0.0587 \times$ hip angular displacement) $[\mathrm{Y}=\mathrm{A}=\mathrm{BX}]$

2- $\quad$ Digital record $=\mathbf{5 . 4 7 6 2}$

$+\quad(0.0469 \times$ hip angular displacement $)+($ 2.342E-05x wrest angular acceleration) $[\mathrm{Y}=\mathrm{A}=\mathrm{B} 1 \mathrm{x} 1+\mathrm{B} 2 \mathrm{x} 2]$

3 - $\quad$ Digital record $=5.9438$ $+(0.0376$ x hip angular displacement $)+(\mathbf{2 . 2 0 0 E - 0 5 x}$ wrest angular acceleration) + ($0.0323 \mathrm{x}$ shoulder angular displacement)

$[\mathrm{Y}=\mathrm{A}=\mathrm{B} 1 \mathrm{x} 1+\mathrm{B} 2 \mathrm{x} 2+\mathrm{B} 3 \times 3]$

4- $\quad$ Digital record $=2.7681$

$+(0.0470 \times$ hip angular displacement $)+(\mathbf{5 . 5 0 0 E}-05 \mathrm{x}$ wrest angular acceleration) + $(0.1013 \mathrm{x}$ shoulder angular displacement $)+(-3.144 E-03 x$ ankle angular velocity) $[\mathrm{Y}=\mathrm{A}=\mathrm{B} 1 \mathrm{x} 1+\mathrm{B} 2 \mathrm{x} 2+\mathrm{B} 3 \mathrm{x} 3+\mathrm{B} 4$ $\mathrm{x} 4]$

5- $\quad$ Digital record $=4.0799$ $+(0.0574 \times$ hip angular displacement $)+(\mathbf{8 . 8 4 0 E - 0 5 x}$ wrest angular acceleration) + $(0.1085 \mathrm{x}$ shoulder angular displacement $)+(-3.999 E-03 x$ ankle angular velocity)+($0.0180 \mathrm{x}$ wrest angular displacement)

$[\mathrm{Y}=\mathrm{A}=\mathrm{B} 1 \mathrm{x} 1+\mathrm{B} 2 \mathrm{x} 2+\mathrm{B} 3 \mathrm{x} 3+\mathrm{B} 4$ $\mathrm{x} 4+\mathrm{B} 5 \mathrm{x} 5]$

6- $\quad$ Digital record $=2.871+$ $(0.0598 \quad \mathrm{x}$ hip angular displacement $)+(9.974 E-05 x$ wrest angular acceleration) + $(0.1181 \mathrm{x}$ shoulder angular displacement $)+(-4.584 E-03 x$ ankle angular velocity) + ($0.0155 \mathrm{x}$ wrest angular displacement $)+(\mathbf{1 . 2 5 7 E - 0 5 x}$ elbow angular acceleration) $[\mathrm{Y}=\mathrm{A}=\mathrm{B} 1 \mathrm{x} 1+\mathrm{B} 2 \mathrm{x} 2+\mathrm{B} 3 \times 3+\mathrm{B} 4$ $\mathrm{x} 4+\mathrm{B} 5 \mathrm{x} 5+\mathrm{B} 6 \mathrm{x} 6]$

7 - Digital record $=2.8735$ $+(0.0583 \times$ hip angular displacement $)+(\mathbf{9 . 8 7 4 E - 0 5} \mathrm{x}$ wrest angular acceleration) + $(0.1160 \mathrm{x}$ shoulder angular displacement $)+(-4.581 E-03 x$ ankle angular velocity) + ($0.0155 \mathrm{x}$ wrest angular displacement $)+(\mathbf{1 . 2 5 7 E - 0 5} \mathrm{x}$ elbow angular acceleration) + (3.905E-07x hip angular velocity)

$[\mathrm{Y}=\mathrm{A}=\mathrm{B} 1 \mathrm{x} 1+\mathrm{B} 2 \mathrm{x} 2+\mathrm{B} 3 \mathrm{x} 3+\mathrm{B} 4$ $\mathrm{x} 4+\mathrm{B} 5 \mathrm{x} 5+\mathrm{B} 6 \mathrm{x} 6+\mathrm{B} 7 \mathrm{x} 7]$ 
Table (8) 
Table (9)

Regression analysis of angular kinematic variables at the beginning of damping for second takeoff

\begin{tabular}{|c|c|c|c|c|c|c|}
\hline Indicators & $\begin{array}{c}\text { Standard } \\
\text { Error }\end{array}$ & Constant & $\mathbf{F}$ & \multicolumn{2}{|c|}{$\begin{array}{l}\text { Regression } \\
\text { Coefficient }\end{array}$} & $\begin{array}{c}\text { Relative } \\
\text { contribution }\end{array}$ \\
\hline $\begin{array}{c}\text { Elbow } \\
\text { angular } \\
\text { displacement }\end{array}$ & 0.2593 & 20.991 & 125.487 & $\begin{array}{c}- \\
0.0566\end{array}$ & & 89.20 \\
\hline $\begin{array}{c}\text { Elbow } \\
\text { angular } \\
\text { displacement } \\
+ \text { ankle } \\
\text { angular } \\
\text { acceleration }\end{array}$ & 0.1489 & 19.225 & 204.922 & $\begin{array}{c}- \\
0.0441\end{array}$ & $\begin{array}{c}- \\
5.341 \mathrm{E}- \\
0\end{array}$ & 96.50 \\
\hline
\end{tabular}

Predicative equations:

1. Digital record $=20.991+(-$ $0.0566 \quad \mathrm{x}$ elbow angular displacement) $[\mathrm{Y}=\mathrm{A}=\mathrm{BX}]$

2. Digital record $=19.225+(-$

$0.0441 \quad \mathrm{x}$ elbow angular displacement $)+(-5.341 E-0 \times$ ankle angular acceleration) $[\mathrm{Y}=\mathrm{A}=\mathrm{B} 1 \times 1+\mathrm{B} 2 \times 2]$ 
Table (10) 
Table (11)

Regression analysis of angular kinematic variables at end of damping/ beginning of pushing for second takeoff

\begin{tabular}{|c|c|c|c|c|c|c|c|c|}
\hline Indicators & $\begin{array}{c}\text { Standard } \\
\text { Error }\end{array}$ & Constant & $\mathbf{F}$ & \multicolumn{4}{|c|}{ Regression Coefficient } & $\begin{array}{c}\text { Relative } \\
\text { contribution }\end{array}$ \\
\hline $\begin{array}{c}\text { angular } \\
\text { displacement }\end{array}$ & 0.2272 & 32.3073 & 167.785 & $0 . \overline{1332}$ & & & & 91.70 \\
\hline $\begin{array}{c}\text { Knee } \\
\text { angular } \\
\text { displacement } \\
+ \text { ankle } \\
\text { angular } \\
\text { displacement }\end{array}$ & 0.1910 & 30.2620 & 122.147 & $\begin{array}{c}- \\
0.0810\end{array}$ & $\begin{array}{c}- \\
0.0534\end{array}$ & & & 94.20 \\
\hline $\begin{array}{c}\text { Knee } \\
\text { angular } \\
\text { displacement } \\
+ \text { ankle } \\
\text { angular } \\
\text { displacement } \\
+ \text { shoulder } \\
\text { angular } \\
\text { displacement }\end{array}$ & 0.1229 & 39.5501 & 203.032 & $0 . \overline{1283}$ & $\begin{array}{c}- \\
0.0698\end{array}$ & $0 . \overline{1562}$ & & 97.60 \\
\hline $\begin{array}{c}\text { Knee } \\
\text { angular } \\
\text { displacement } \\
\text { + ankle } \\
\text { angular } \\
\text { displacement } \\
\text { + shoulder } \\
\text { angular } \\
\text { displacement } \\
\text { + ankle } \\
\text { angular } \\
\text { acceleration }\end{array}$ & 0.0814 & 39.6855 & 350.914 & 0.1383 & 0.0566 & 0.1806 & $\begin{array}{l}4.31 \mathrm{E}- \\
05\end{array}$ & 98.90 \\
\hline
\end{tabular}

Predicative equations:

1. $\quad$ Digital record $=32.3073+(-$ $0.1332 \times$ knee angular displacement) $[\mathrm{Y}=\mathrm{A}=\mathrm{BX}]$

2. Digital record $=30.2620+(-$ $0.0810 \mathrm{x}$ knee angular displacement) $+\quad(-0.0534 \times$ ankle angular displacement) $[\mathrm{Y}=\mathrm{A}=\mathrm{B} 1 \mathrm{x} 1+\mathrm{B} 2 \mathrm{x} 2]$

3. Digital record $=39.5501+(-$ $0.1283 \mathrm{x}$ knee angular displacement) $+\quad(-0.0698 \times$ ankle angular displacement $)+(-0.1562 \times$ shoulder angular

displacement)

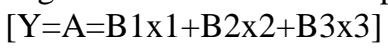

4. Digital record $=39.6855+(-$

$0.1383 \mathrm{x}$ knee angular displacement)

$+\quad(-0.0566$ x ankle angular displacement $)+(-0.1806 \times$ shoulder angular displacement) + (4.31E05x ankle angular acceleration) $[\mathrm{Y}=\mathrm{A}=\mathrm{B} 1 \mathrm{x} 1+\mathrm{B} 2 \mathrm{x} 2+\mathrm{B} 3 \times 3+\mathrm{B} 4 \mathrm{x} 4]$ 
Table (12) 
Table (13)

Regression analysis of angular kinematic variables at end of pushing for second takeoff

\begin{tabular}{|c|c|c|c|c|c|c|c|}
\hline Indicators & $\begin{array}{c}\text { Standard } \\
\text { Error }\end{array}$ & Constant & $\mathbf{F}$ & \multicolumn{3}{|c|}{ Regression Coefficient } & $\begin{array}{c}\text { Relative } \\
\text { contribution }\end{array}$ \\
\hline $\begin{array}{c}\text { Ankle angular } \\
\text { displacement }\end{array}$ & 0.1738 & 2.9330 & 296.4931 & $\begin{array}{c}0.0 \\
954\end{array}$ & & & 95.20 \\
\hline $\begin{array}{c}\text { Ankle angular } \\
\text { displacement } \\
+ \text { ankle } \\
\text { angular } \\
\text { velocity } \\
\end{array}$ & 0.1376 & 4.6106 & 241.3009 & 0.0873 & $\begin{array}{c}- \\
9.233 \mathrm{E}- \\
0\end{array}$ & & 97.00 \\
\hline $\begin{array}{l}\text { Ankle angular } \\
\text { displacement } \\
+ \text { ankle } \\
\text { angular } \\
\text { velocity + hip } \\
\text { angular } \\
\text { displacement }\end{array}$ & 0.1117 & 5.7916 & 246.5993 & 0.1163 & -0.0013 & $0 . \overline{-} 32$ & 98.00 \\
\hline $\begin{array}{l}\text { Predicative } \\
1 . \quad \text { Digi } \\
0.0954 \times \text { anl } \\
{[\mathrm{Y}=\mathrm{A}=\mathrm{BX}]} \\
2 . \quad \text { Digi } \\
(0.0873\end{array}$ & $\begin{array}{l}\text { quations: } \\
\text { al record } \\
\text { le angular } \\
\text { al } r \text { record } \\
\text { x } r \text { ank }\end{array}$ & $\begin{array}{l}=2.9330 \\
\text { displacem }\end{array}$ & ent) & $\begin{array}{l}. \\
(0.116 \\
\text { displac } \\
\text { angular } \\
\text { angular } \\
{[\mathrm{Y}=\mathrm{A}=}\end{array}$ & 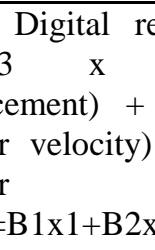 & $\begin{array}{r}\text { ecord }= \\
\text { ankle } \\
(-0.00 \\
+(-0 \\
\mathrm{d} \\
\mathrm{x} 2+\mathrm{B} 3 \mathrm{x}\end{array}$ & $\begin{array}{l}5.7916+ \\
\text { angular } \\
3 \times \text { ankle } \\
0232 \times \text { hip } \\
\text { splacement) } \\
\text { ] }\end{array}$ \\
\hline
\end{tabular}

displacement $)+(-9.233 E-0 x$ ankle angular velocity) $[\mathrm{Y}=\mathrm{A}=\mathrm{B} 1 \mathrm{x} 1+\mathrm{B} 2 \mathrm{x} 2]$

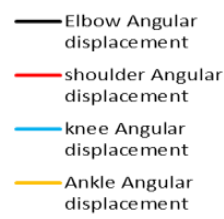

Figure (1): Dynamics of Angular displacement for the elbow, shoulder, knee and ankle during 


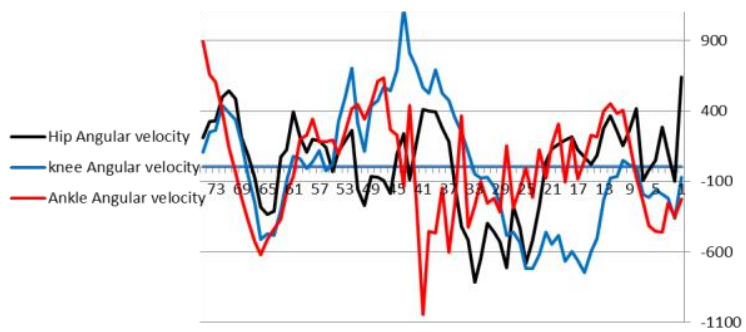

Figure (2): Dynamics of Angular velocity for the hip, knee and ankle during the first and second takeoff
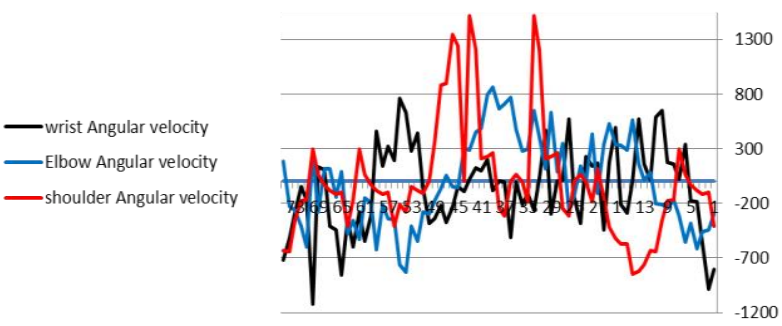

Time

Figure (3): Dynamics of Angular velocity for the wrist, elbow and shoulder during the first and second takeoff

Discussion:

Table (3) indicates that knee angular displacement is the first important variable affecting digital record at the beginning of damping for first takeoff with relative contribution of $90.30 \%$. This is because the knee plays a major role during the hop as triple jumpers need horizontal displacement more than vertical displacement with consistent rhythm. This is consistent with Bastawisy Mohamed (1997) and Susan Hall (2000) (11: 292) (19: 364).
The second important variable affecting digital record at the beginning of damping for first takeoff was shoulder angular displacement as it raised relative contribution from $90.30 \%$ to $94.80 \%(4.5 \%)$. This is due to the importance of arm movements during takeoff, especially at the beginning of damping, as momentum transfers from limps to trunk. This is in agreement with Sawsan Abd El-Monem et al (1991), Talha Husam El-Din (1994) and Berequaa \& Al-Sokkary (2002) (2: $156,228)(16: 26,27)(12: 189)$. 


\section{3}

The third important variable affecting digital record at the beginning of damping for first takeoff was hip angular acceleration as it raised relative contribution from $98.80 \%$ to $97.60 \%$ (2.8\%). This is due to the movement of thigh towards trunk at that portion of movement. This increases the importance of angular displacement at the beginning of the hop and therefore increasing the hip angular acceleration. This is in agreement with Sawsan Abd El-Monem et al (1991) and Ali Abd El-Rahman and Talha Husam El-Din (1994) (2: 138, 139) (3: 224).

The fourth important variable affecting digital record at the beginning of damping for first takeoff was ankle angular displacement as it raised relative contribution from $97.60 \%$ to $99.10 \%(1.5 \%)$. This is due to the angular change in foot and leg because of the collision of foot with takeoff board and leg turning around the horizontal axis in addition to the pushing force of takeoff till reaching the highest point of hop and the increase of hop distance without turning right or left. This is in agreement with Talha Husam El-Din (1994) and Berequaa \& Al-Sokkary (2002) (15: 316, 317) (12: 51-54).

The fifth important variable affecting digital record at the beginning of damping for first takeoff was knee angular acceleration as it raised relative contribution from $99.10 \%$ to $99.40 \% \quad(0.30 \%)$. Acceleration decreases as when hitting the floor at landing the decreased acceleration prepares legs to keep balance without drifting right or left. This is consistent with Bastawisy Mohamed (1997) and Osama Zaki (2006) (11: 302-303) (20: 88).

Tables (5 and 11) indicate that ankle angular velocity is the first important variable affecting digital record at the end of damping/ beginning of push for first takeoff with relative contribution of $88.10 \%$. During the end of damping/ beginning of push for second takeoff (table 11), ankle angular displacement raised relative contribution from $91.70 \%$ to $94.20 \%$ $(2.5 \%)$ while ankle angular acceleration raised relative contribution from $97.60 \%$ to $98.90 \%$ $(1.3 \%)$. This is because of the angular change in foot and leg due to the movement quickness especially at the ankle at the beginning of pushing. This produced angular displacement and angular velocity at the ankle. Angular acceleration increases with the increase of angular velocity. This is consistent with Bridgett (2002), Talha Husam El-Din (1993) and Berequaa \& Al-Sokkary (2002) (13: 80-84) (15: 316-317) (12: 51-54). 
Tables (5 and 11) indicate that knee angular displacement is the second important variable affecting digital record at the end of damping/ beginning of push for first takeoff as raised relative contribution from $88.10 \%$ to $92.30 \%$ (4.2\%). For the same variable at the second takeoff, relative contribution was $91.70 \%$. This is because of the important role of knee extensors at the beginning of the push as triple jumpers need horizontal displacement more than vertical displacement with consistent rhythm. This is consistent with Bastawisy Mohamed (1997) and Susan Hall (2000) (11: 292) (19: 364).

Tables (7 and 13) indicate that hip angular displacement is the first important variable affecting digital record at the end of push for first takeoff with relative contribution of $84 \%$. At second takeoff, the same variable raised relative contribution from $97 \%$ to $98 \%(1 \%)$. This is due to the extension of thigh and pushing the floor hard with full use of leg joints' range of motion at the end of pushing. This increases the importance of hip angular displacement. This is consistent with Sawsan Abd El-Monem et al (1991) and Ali Abd El-Rahman and Talha Husam El-Din (1994) (2: 138-139) (3: 224).
Table (7) indicate that wrest angular acceleration is the second important variable affecting digital record at the end of push for first takeoff as raised relative contribution from $84 \%$ to $88.10 \% \quad(4.1 \%)$. Shoulder angular displacement is the third important variable affecting digital record at the end of push for first takeoff as raised relative contribution from $88.10 \%$ to $91 \%$ $(2.9 \%)$. This is due to the importance of arm velocity, especially at the shoulder and wrest joints. This produces angular displacements for these two joints. The increase of wrest angular displacement led to increasing the angular velocity and angular acceleration at the end of pushing as momentum is transferred from limps to trunk. This is consistent with Sawsan Abd ElMonem et al (1991), Talha Husam El-Din (1994) and Berequaa \& AlSokkary (2002) (2: 156, 228) (16: 26, 27) (12: 189).

Tables (7 and 13) indicate that ankle angular velocity is the fourth important variable affecting digital record at the end of push for first takeoff as raised relative contribution from $91 \%$ to $95.90 \%$ $(4.9 \%)$. As for the second takeoff ankle angular displacement came first with relative contribution of $95.20 \%$ while ankle angular velocity came second as it raised relative 
contribution from $95.20 \%$ to $97 \%$ $(1.8 \%)$. This is because of the angular change in foot and leg due to the movement quickness especially at the ankle at the end of pushing with the increase of hop distance and consequently bounce distance without any deviation to right or left. This is consistent with Bridgett (2002), Talha Husam El-Din (1993) and Berequaa \& Al-Sokkary (2002) (13: 80-84) (15: 316-317) (12: 5154).

Table (7) indicate that wrest angular displacement is the fifth important variable affecting digital record at the end of push for first takeoff as raised relative contribution from $95.90 \%$ to $99.60 \%$ (3.7\%) while the sixth variable is elbow angular acceleration as it raised relative contribution from $99.60 \%$ to $99.80 \%$ $(0.20 \%)$. This is due to the importance of arm and wrest quickness which produces wrest and elbow angular displacement. This increased the angular velocity and angular acceleration of elbow at the end of pushing while momentum is transferred from limps to trunk. This is consistent with Sawsan Abd ElMonem et al (1991), Talha Husam El-Din (1994) and Berequaa \& AlSokkary (2002) (2: 156, 228) (16: 26,27) (12: 189).

Table (7) indicate that hip angular velocity is the seventh important variable affecting digital record at the end of push for first takeoff as raised relative contribution from $99.80 \%$ to $100 \%(1.2 \%)$. This is due to extension of thigh joint, pushing the floor hard and using full extension of leg joints at the end of pushing. This increases hip angular displacement and angular velocity. This is consistent with Sawsan Abd El-Monem et al (1991) and Ali Abd El-Rahman and Talha Husam El-Din (1994) (2: 138-139) (3: 224).

Table (9) indicated that elbow angular displacement is the first important variable affecting digital record at the beginning of damping for second takeoff with relative contribution of $89.20 \%$. this is due to the importance of arm movement producing elbow angular displacement while momentum transfers from limp[s to trunk. This is consistent with Sawsan Abd ElMonem et al (1991), Talha Husam El-Din (1994) and Berequaa \& AlSokkary (2002) (2: 156, 228) (16: 26, 27) (12: 189).

Table (9) also indicate that ankle angular acceleration is the second important variable affecting digital record at the beginning of damping for second takeoff as raised relative contribution from $89.20 \%$ to $96.50 \%(7.3 \%)$. This is because of the angular change in foot and leg due to the movement quickness 
especially at the ankle at the beginning of damping where angular velocity, and consequently angular acceleration, increases. This is consistent with Talha Husam El-Din (1993) and Berequaa \& Al-Sokkary (2002) (15: 316-317) (12: 51-54)

Table (11) indicate that shoulder angular displacement is the third important variable affecting digital record at the end of damping/ beginning of push for second takeoff as raised relative contribution from $94.20 \%$ to $97.60 \%(3.4 \%)$. This is due to the importance of arm movement, especially at the shoulder joint. This produces angular displacement at the beginning of pushing with momentum transferring from limps to trunk. This is consistent with Sawsan Abd ElMonem et al (1991), Talha Husam El-Din (1994) and Berequaa \& AlSokkary (2002) (2: 156, 228) (16: 26, 27) (12: 189).

\section{Conclusions:}

According to these results, the researcher concluded the following:

A. Indicators contributing in the digital record at the beginning of damping for first takeoff are knee angular displacement, shoulder angular displacement, hip angular acceleration, ankle angular displacement and knee angular acceleration.
Predicative equations:

$(\mathrm{Y}=$ dependent variable $-\mathrm{A}=$ constant $-\mathrm{B}=$ regression coefficient $\mathrm{X}=$ independent variable)

6. Digital record $=4.8257+$ (0.06354 $\mathrm{X}$ knee angular displacement) $[\mathrm{Y}=\mathrm{A}+\mathrm{BX}]$

7. Digital record $=6.1784+$ $(0.04957 \quad x \quad$ knee angular displacement $)+(0.02112 \times$ shoulder angular displacement) [Y=A+B1x1+B2x2]

8. Digital record $=7.7985+$ $(0.03838 \quad x \quad$ knee angular displacement $)+(0.02183 \times$ shoulder angular displacement $)+(-0.00004 \mathrm{x}$ hip angular acceleration) $[\mathrm{Y}=\mathrm{A}+\mathrm{B} 1 \mathrm{x} 1+\mathrm{B} 2 \mathrm{x} 2+\mathrm{B} 3 \times 3]$

9. Digital record $=7.5054+$ $(0.06706 \mathrm{x}$ knee angular displacement $)+(0.00624 \times$ shoulder angular displacement $)+(-0.00006 \mathrm{x}$ hip angular acceleration $)+(-0.02854$ $\mathrm{X}$ ankle angular displacement $[\mathrm{Y}=\mathrm{A}+\mathrm{B} 1 \mathrm{x} 1+\mathrm{B} 2 \times 2+\mathrm{B} 3 \times 3+\mathrm{B} 4 \times 4]$

10. Digital record $=8.8261+$ $(0.08301 \quad \mathrm{x}$ knee angular displacement $)+(0.01207 \times$ shoulder angular displacement $)+(-0.00007 \mathrm{x}$ hip angular acceleration $)+(-0.05460$ $\mathrm{x}$ ankle angular displacement $+(-$ $0.00003 \times$ knee angular acceleration) $[\mathrm{Y}=\mathrm{A}+\mathrm{B} 1 \mathrm{x} 1+\mathrm{B} 2 \times 2+\mathrm{B} 3 \mathrm{x} 3+\mathrm{B} 4 \mathrm{x} 4+\mathrm{B} 5$ $\mathrm{X} 5]$

B. Indicators contributing in the digital record at the beginning of damping for second takeoff are 
elbow angular displacement and ankle angular acceleration.

Predicative equations:

3. Digital record $=20.991+(-$ $0.0566 \mathrm{X}$ elbow angular displacement) $[\mathrm{Y}=\mathrm{A}=\mathrm{BX}]$

4. Digital record $=19.225+(-$ $0.0441 \quad x \quad$ elbow angular displacement $)+(-5.341 E-0 \times$ ankle angular acceleration) $[\mathrm{Y}=\mathrm{A}=\mathrm{B} 1 \mathrm{x} 1+\mathrm{B} 2 \mathrm{x} 2]$

C. Indicators contributing in the digital record at the end of damping/ beginning of pushing for first takeoff are ankle angular velocity and knee angular displacement.

Predicative equations:

1. Digital record $=11.6888+(-$ $0.0077 \mathrm{x}$ ankle angular velocity) $[\mathrm{Y}=\mathrm{A}=\mathrm{BX}]$

2. Digital record $=19.6456+(-$ $0.0042 \mathrm{x}$ ankle angular velocity) $+(-$ $0.0465 \times$ knee angular displacement) $[\mathrm{Y}=\mathrm{A}=\mathrm{B} 1 \mathrm{x} 1+\mathrm{B} 2 \mathrm{x} 2]$

D. Indicators contributing in the digital record at the end of damping/ beginning of pushing for second takeoff are knee angular displacement, ankle angular displacement, shoulder angular displacement and ankle angular acceleration.

Predicative equations:

5. Digital record $=32.3073+(-$ $0.1332 \times$ knee angular displacement) $[\mathrm{Y}=\mathrm{A}=\mathrm{BX}]$
6. Digital record $=30.2620+(-$ $0.0810 \mathrm{x}$ knee angular displacement) $+\quad(-0.0534 \times$ ankle angular displacement) $[\mathrm{Y}=\mathrm{A}=\mathrm{B} 1 \mathrm{x} 1+\mathrm{B} 2 \mathrm{x} 2]$

7. Digital record $=39.5501+(-$ $0.1283 \mathrm{x}$ knee angular displacement) $+\quad(-0.0698 \times$ ankle angular displacement $)+(-0.1562 \times$ shoulder angular displacement) [Y=A=B1x $1+\mathrm{B} 2 \times 2+\mathrm{B} 3 \times 3$ ]

8. Digital record $=39.6855+(-$ $0.1383 \mathrm{x}$ knee angular displacement) $+\quad(-0.0566 \mathrm{x}$ ankle angular displacement $)+(-0.1806 \times$ shoulder angular displacement) + (4.31E05 $\mathrm{x}$ ankle angular acceleration) $[\mathrm{Y}=\mathrm{A}=\mathrm{B} 1 \mathrm{x} 1+\mathrm{B} 2 \mathrm{x} 2+\mathrm{B} 3 \mathrm{x} 3+\mathrm{B} 4 \mathrm{x} 4]$

E. Indicators contributing in the digital record at the end of pushing for first takeoff are hip angular displacement, wrest angular acceleration, shoulder angular displacement, ankle angular velocity, wrest angular displacement, elbow angular acceleration and hip angular velocity.

Predicative equations:

8- Digital record $=3.1284+$ (0.0587 x hip angular displacement) [Y=A=BX]

9- Digital record $=\mathbf{5 . 4 7 6 2}+$ (0.0469 x hip angular displacement) $+\quad$ (2.342E-05x wrest angular acceleration) $[\mathrm{Y}=\mathrm{A}=\mathrm{B} 1 \mathrm{x} 1+\mathrm{B} 2 \times 2]$

10- Digital record $=5.9438+$ (0.0376 x hip angular displacement)

$+\quad$ (2.200E-05x wrest angular 
acceleration $)+(-0.0323 \times$ shoulder angular displacement) [Y=A=B1 $1+\mathrm{B} 2 \times 2+\mathrm{B} 3 \times 3]$

11- Digital record $=2.7681+$ (0.0470 x hip angular displacement) $+\quad$ 5.500E-05x wrest angular acceleration $)+(0.1013 \mathrm{x}$ shoulder angular displacement $)+(-\mathbf{3 . 1 4 4 E}$ 03 $\mathrm{X}$ ankle angular velocity) $[\mathrm{Y}=\mathrm{A}=\mathrm{B} 1 \mathrm{x} 1+\mathrm{B} 2 \times 2+\mathrm{B} 3 \times 3+\mathrm{B} 4 \times 4]$

12- Digital record $=4.0799+$ (0.0574 x hip angular displacement) $+\quad(8.840 E-05 x$ wrest angular acceleration $)+(0.1085 \times$ shoulder angular displacement $)+(-3.999 E-$ 03x ankle angular velocity)+($0.0180 \mathrm{x}$ wrest angular displacement) $[\mathrm{Y}=\mathrm{A}=\mathrm{B} 1 \mathrm{x} 1+\mathrm{B} 2 \times 2+\mathrm{B} 3 \times 3+\mathrm{B} 4 \mathrm{x} 4+\mathrm{B} 5$ $\mathrm{x} 5]$

13- Digital record $=2.871+$ (0.0598 x hip angular displacement) $+\quad$ 9.974E-05x wrest angular acceleration $)+(0.1181 \times$ shoulder angular displacement $)+(-\mathbf{4 . 5 8 4 E}-$ 03x ankle angular velocity) + ($0.0155 \mathrm{x}$ wrest angular displacement) + (1.257E-05x elbow angular acceleration)

$[\mathrm{Y}=\mathrm{A}=\mathrm{B} 1 \mathrm{x} 1+\mathrm{B} 2 \times 2+\mathrm{B} 3 \times 3+\mathrm{B} 4 \mathrm{x} 4+\mathrm{B} 5$ $\mathrm{x} 5+\mathrm{B} 6 \mathrm{x} 6]$

14- Digital record $=2.8735+$ (0.0583 x hip angular displacement) $+\quad(9.874 E-05 x$ wrest angular acceleration $)+(0.1160 \mathrm{x}$ shoulder angular displacement $)+(-4.581 E-$ 03x ankle angular velocity) + ($0.0155 \mathrm{x}$ wrest angular displacement) $+\quad$ (1.257E-05x elbow angular acceleration $)+(3.905 E-07 x$ hip angular velocity) $[\mathrm{Y}=\mathrm{A}=\mathrm{B} 1 \mathrm{x} 1+\mathrm{B} 2 \times 2+\mathrm{B} 3 \times 3+\mathrm{B} 4 \times 4+\mathrm{B} 5$ $\mathrm{x} 5+\mathrm{B} 6 \mathrm{x} 6+\mathrm{B} 7 \mathrm{x} 7]$

F. Indicators contributing in the digital record at the end of pushing for Second takeoff are ankle angular displacement, ankle angular velocity and hip angular displacement.

Predicative equations:

4. $\quad$ Digital record $=2.9330+(-$ $0.0954 \mathrm{x}$ ankle angular displacement) $[\mathrm{Y}=\mathrm{A}=\mathrm{BX}]$

5. Digital record $=4.6106+$ $(0.0873 \mathrm{x}$ ankle angular displacement $)+(-9.233 \mathrm{E}-0 \mathrm{x}$ ankle angular velocity) $[\mathrm{Y}=\mathrm{A}=\mathrm{B} 1 \mathrm{x} 1+\mathrm{B} 2 \times 2]$ 6. Digital record $=5.7916+$ $(0.1163 \mathrm{x}$ ankle angular displacement $)+(-0.0013 \times$ ankle angular velocity $)+(-0.0232 \times$ hip angular displacement)

$[\mathrm{Y}=\mathrm{A}=\mathrm{B} 1 \mathrm{x} 1+\mathrm{B} 2 \times 2+\mathrm{B} 3 \times 3]$

\section{Recommendations:}

In the light of these conclusions, the researcher recommends that:

1- Indicators under investigation that proved to be affecting the digital record of triple jump should be used, along with its predicative equations, in selecting triple jumpers

2- Training programs for the hop stage of triple jump should be designed in the light of these indicators and predicative equations 


\section{References:}

1- Abd El-Halim, A. M. et al (2003): Theory and Application of Track and Field Events: Part Three (teaching - technique laws). Alexandria - Egypt (in Arabic)

2- Abd El-Monem, S.; Omar, M. S. \& Ragheb, M. A. (1991): Biomechanics in Sport: Part One (Biodynamic). Alexandria - Egypt (in Arabic)

3- Abd El-Rahman, A. M. \& Husam El-Din, T. (2001): Sports kinesiology and basics of motor analysis. Dar Al-Fikr Al-Araby - Cairo - Egypt (in Arabic)

4- Abd El-Rahman, Gihan H. (2010): Investigating some biomechanical variables of pivoting phase in triple jump and its relation to flight trajectory and performance level. PhD thesis, Faculty of Physical Education for Women - ZAGAZIG University (in Arabic)

5- Adrian, M.J. Cooper, J.M., (1995): Biomechanics of Human Movement, Brown Benchrnark com., 2nd, U.S.A, 1995

6- Alaa El-Din, Gamal \& AlSabbagh, Nahed A. (2007): Metrological bases for evaluating physical, technical and tactical performance of athletes. Munshaat Al-Maaref Alexandria - Egypt (in Arabic)

7- Al-Gebaly, Owais A. (2001): Sports Training: Theory and Application. $1^{\text {st }}$ ED. GMS Press - Cairo - Egypt (in Arabic).

8- Ali, Adel A. (1998): Biomechanics: integration of theory and application in sport. $8^{\text {th }}$ ED. Markaz Al-Ketab Press, Cairo - Egypt (in Arabic).

9- Al-Sabbagh, Nahed A. \& Alaa El-Din Gamal M. (1999): Kinesiology. $7^{\text {th }}$ ED. Faculty of Physical Education for Men Alexandria University (in Arabic)

10- Bashir, Moamer Adam (2010): Bio kinematic Analysis of Sudanese Triple Jumpers. Master Thesis. Faculty of Physical Education for Men HELWAN University (in Arabic)

11- Bastawisy, Bastawisy A. (1997): Track and Field Events (teaching - technique training). Dar Al-Fikr Al-Araby - Cairo - Egypt (in Arabic)

12- Berequaa, M. G. \& AlSokkary, K. I. (2002): Principles of Biomechanics in Sport, Part One. Munshaat AlMaaref - Alexandria - Egypt (in Arabic)

13- Bridgett,L.,Galloway, 
M.,Linthorne, N. (2002): The effect of Run- up Speed on Long Jump performance. International symposium on Biomechanics in Sport.xx, 2002

14- Hay J.G. (1997): Phase Distances Percentages, and techniques In the men's Triple jump at the 1996 U. S. A Olympic trials, track coach for merly Track Technique No 139. 1997

15- Husam El-Din, Talha (1993): Biomechanics: Theoretical and Applied Bases. $1^{\text {st }}$ ED. Dar AlFikr Al-Araby - Cairo - Egypt (in Arabic)

16- Husam El-Din, Talha (1994): Motor and Functional Bases of Sports Training. Dar Al-Fikr Al-Araby - Cairo - Egypt (in Arabic)

17- Jae Kyun,Chang Hwan Kim,Young Jun Park (1995): Kinematic Analysis Of Triple Jump, 18th sea Games Scientific Congress December 5-8, 1995 Chang Mai, Thailand

18- Khalil, Mohamed A. (1993): Analyzing World Records of Triple Jump from 1911 to 1985. Athletics Periodical,
No.8 - Cairo - Egypt (in Arabic).

19- Susan J.Hall (2000): Basie of Biomedmics of Athletics 9 th Biddlisl, TD, Guilford, London, 2000

20- Zaky, Osama A. (2006): Effectiveness of using biomechanical indicators ass standards for improving performance of long jump. $\mathrm{PhD}$ thesis, Faculty of Physical Education for Men ZAGAZIG University (in Arabic).

25- http://ar.wikipedia.org/wiki/ \%D8\%A8\%D8\%B7\%D9\%88\%D9\% 84\%D8\%A9_\%D8\%A7\%D9\%84\%D 8\%B9\%D8\%A7\%D9\%84\%D9\%85_ \%D9\%84\%D8\%A3\%D9\%84\%D8\% B9\%D8\%A7\%D8\%A8_\%D8\%A7\% D9\%84\%D9\%82\%D9\%88\%D9\%89 _2013

26-http://ar.wikipedia.org/wiki/\%D9 $\% 82 \% \mathrm{D} 9 \% 81 \% \mathrm{D} 8 \% \mathrm{~B} 2 \_\% \mathrm{D} \% \mathrm{AB}$ $\% \mathrm{D} 9 \% 84 \% \mathrm{D} 8 \% \mathrm{~A} 7 \% \mathrm{D} 8 \% \mathrm{AB} \% \mathrm{D} 9 \%$ $8 \mathrm{~A}$

27-http://en.wikipedia.org/wiki/2012 _African_Championships_in_Athleti cs

28-https://www.facebook.com/arabat hletics 2013

29-http://www.london2012.com 